\title{
Collaborative Networks among Local Governments in the Seoul Metropolitan Area in South Korea
}

\author{
Youngmi Lee ${ }^{1}$ \\ ${ }^{1}$ Department of Public Administration, Kyonggi University, South Korea \\ Correspondence: Youngmi Lee, Department of Public Administration, Kyonggi University, 154-42 \\ Gwanggyosan-ro, Yeongtong-gu, Suwon-si, Gyeonggi-do, South Korea. Tel: 82-31-249-9319. E-mail: \\ ymlee@kyonggi.ac.kr
}

Received: September 15, 2014 Accepted: October 9, $2014 \quad$ Online Published: December 20, 2014

doi:10.5539/ass.v11n2p238

URL: http://dx.doi.org/10.5539/ass.v11n2p238

\begin{abstract}
Objective: This study aims to examine collaborative relationships among local governments in the Seoul metropolitan area in South Korea by applying social network analysis. Background: The capital metropolitan area consists of three upper-level local governments: Seoul, Incheon, and Kyounggi, which consists of 25, 10, and 31 lower-level local governments, respectively. Individual local governments in this competitive environment have sometimes tried to collaborate with each other for regional economic development and growth. This study investigated how they have collaborated with each other, and identified who played key roles in regional networks. Methods: The study applied social network theories and used the UCINET 6 software for an analysis of the network data collected, and the collaborative network among local governments was visualized using NetDraw. Results: The three upper-level local governments played important roles in promoting regional economic growth and coordinating the service delivery system in the capital metropolitan area. Conclusions: This study helps to understand collaborative mechanisms among individual local governments within a fragmented and competitive environment.
\end{abstract}

Keywords: collaborative networks, local governance, social network analysis

\section{Introduction}

The issue as to whether fragmentation or concentration is more efficient in providing public services in the urban setting has been debated continuously in studies of urban administration and policy (Feiock, 2004; Oakerson, 1999; Tiebout, 1961). Because the central government has delegated power and authority to local governments with reduced physical and financial support, individual local municipalities who have secured some degree of autonomy have competed with each other to develop their local economies and to provide public services for their citizens (Lee et al., 2012). However, sometimes this intense competition among local jurisdictions has resulted in inefficiency, causing redundant investments and negative external economic effects (Feiock \& Scholz, 2010). In order to keep the advantages of local autonomy with a fragmented local system and, at the same time, to secure the efficiency of economies of scale by a concentrated urban system, local jurisdictions started to consider voluntarily collaborating with other municipalities (Lee et al., 2012; Feiock, 2004). Collaborative relationships among local jurisdictions can increase the capacity of local jurisdictions to solve common economic problems (Gordon, 2007). Thus, local governments have searched for cooperative partners for their local economic growth, and even forged collaborative relationships with other local jurisdictions with which they previously competed.

Previous research regarding collaborative governance has started to focus on this phenomenon. However, it typically took normative approaches by discussing the concepts and classifying the structures of collaboration and networks, rather than empirically examining how collaboration emerge and are sustained. This study focuses on the collaboration phenomena as a viable strategy for economic prosperity among local jurisdictions, and tries to empirically analyze their networked relationships operate. Specifically, this study examined how collaborations among local governments pursuing win-win symbiosis happen in the Seoul metropolitan area in South Korea, applying social network analysis, and which governmental entities played key roles in such regional collaborative networks. This study helps to understand collaborative mechanisms among individual local governments within a fragmented and competitive environment. 


\section{Data and Methods}

In order to examine the collaboration among local governments in the Seoul metropolitan area, this study collected data on cooperative projects implemented by each local government in 2008 . The local self-governing system in South Korea is a two-tier system: the upper- and lower-level local governments. The lower-level local jurisdictions geographically 'belong' to the upper-level local jurisdictions, and are institutionally, politically, and financially influenced by the rules or policies of the upper-level local governments. The Seoul metropolitan area, the biggest in South Korea, consists of three upper-level local governments: Seoul, Incheon, and Kyounggi, which consists of 25,10 , and 31 lower-level local governments, respectively, and those municipalities, have actively cooperated for regional economic growth and efficient public service delivery.

Data regarding collaboration among local governments was collected based on local project documents and interviews with public servants who were in charge of economic development policy and public service delivery in 2008. In total, 20 of the 25 jurisdictions in Seoul, 31 of the 31 jurisdictions in Kyonggi-do, and two of 10 jurisdictions in Incheon have participated in collaborative projects or programs for regional development in the capital metropolitan area. Those local governments have also collaborated with other jurisdictions outside the capital metropolitan area, of which there are 90 further jurisdictions. Although these 90 jurisdictions are outside the geographic boundary, this study includes them because the upper- and lower-level local governments within the capital metropolitan area have interacted with them to improve economic conditions and to provide convenience for citizens in the metropolitan area.

Table 1. Descriptive network statistics: Links between actors

\begin{tabular}{ll}
\hline & Overall Networks \\
\hline No. of Observation & 72 \\
Dyadic Counts & 2556 \\
Mutual & 308 \\
Null & 2248 \\
Network Density & 0.1205 \\
Average Degree & 8.5556 \\
\hline
\end{tabular}

UCINET 6 for Windows was used as a software package for the analysis of social network data (Borgatti et al., 2002). Table 1 presents descriptive network statistics on the collaborative relations among the 72 local governments included in the study. Approximately $87.9 \%$ of the dyads between local governments were null, indicating no relationship between the two municipalities. This yields an overall network density of 0.1205 . This suggests that in South Korea, collaborative relationships for regional economic development in the capital metropolitan area were not utilized as a development strategy yet. Individual local governments focus on competing with other local jurisdictions in order to secure more resources for their local economic growth and to attract businesses into their own areas in the early stages of a local self-governing system (Wright, 1984). Then, local governments started considering collaboration with other jurisdictions, recognizing that highly intense competition results in inefficiencies, such as negative externalities and redundant investments (Wright, 1984). Based on the results, this study suggest that since the local self-governing system in South Korea began in earnest in 1995, the relationships among local governments have gradually moved from competition to collaboration.

\section{Results}

\subsection{Visualization}

In Figure 1, each node represents individual local governments and each tie indicates a collaborative relationship for regional economic growth and public service delivery in the Seoul metropolitan area in South Korea. Figure 1 shows that the upper-level local governments play important roles in coordinating the relationships among individual local jurisdictions in the capital metropolitan area. In particular, local governments are more likely to cooperate with others who belong to the same upper-level government. For example, local governments that belong to Seoul have actively collaborated with others within Seoul. The findings help us to understand a regional collaborative mechanism in South Korea: because the lower-level local governments within the same upper-level jurisdiction are inclined to face similar economic situations or public problems and are operated by similar institutions or rules, they are more likely to actively collaborate with municipalities that belong to the 
same upper-level government.

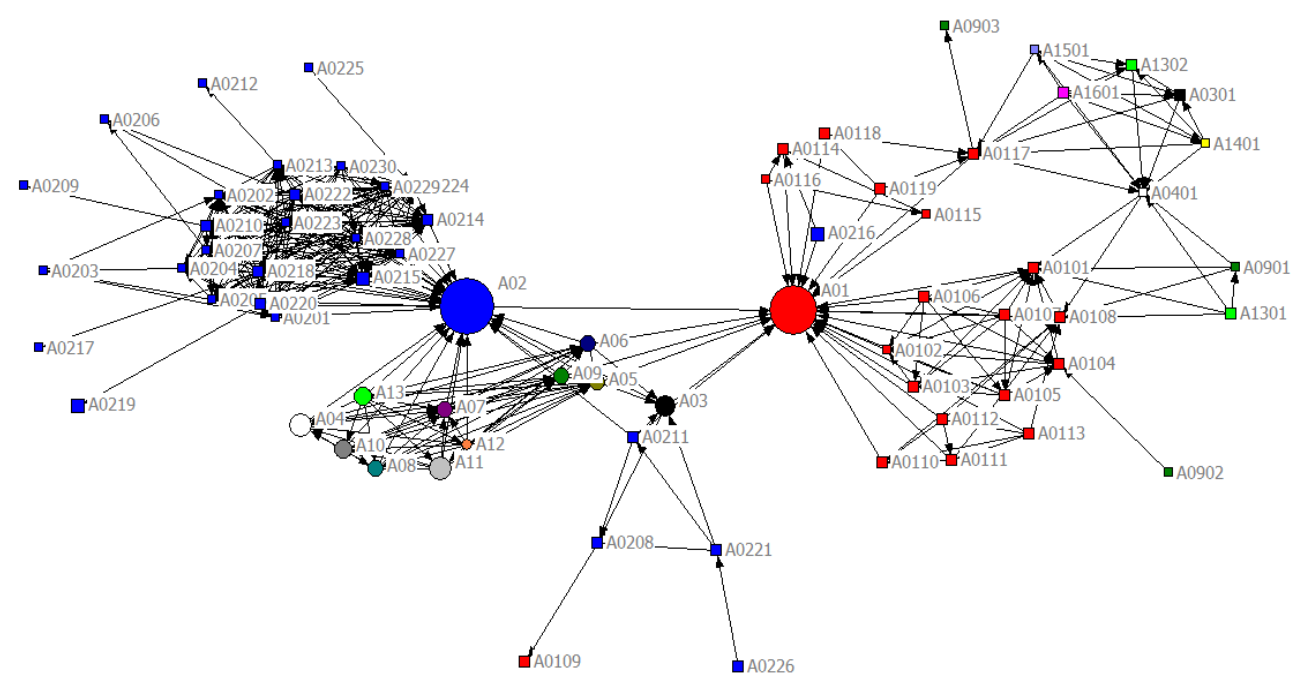

Figure 1. Intergovernmental collaborative networks in capital metropolitan area in South Korea

* Circles: Upper-Level Local Government;

* Squares: Lower-Level Local Government;

* Black Solid Lines: Relationships among Actors;

* Size of Circles and Squares: Based on Population;

* Circles and Squares with Same Color: Local Governments Belong to the Same Upper Level-Local Government.

\subsection{Network Analysis}

In order to further assess this visualized finding, this study calculated the values of three centrality measures for each local government: degree, closeness, and betweenness centralities.

3.2.1 Degree Centrality

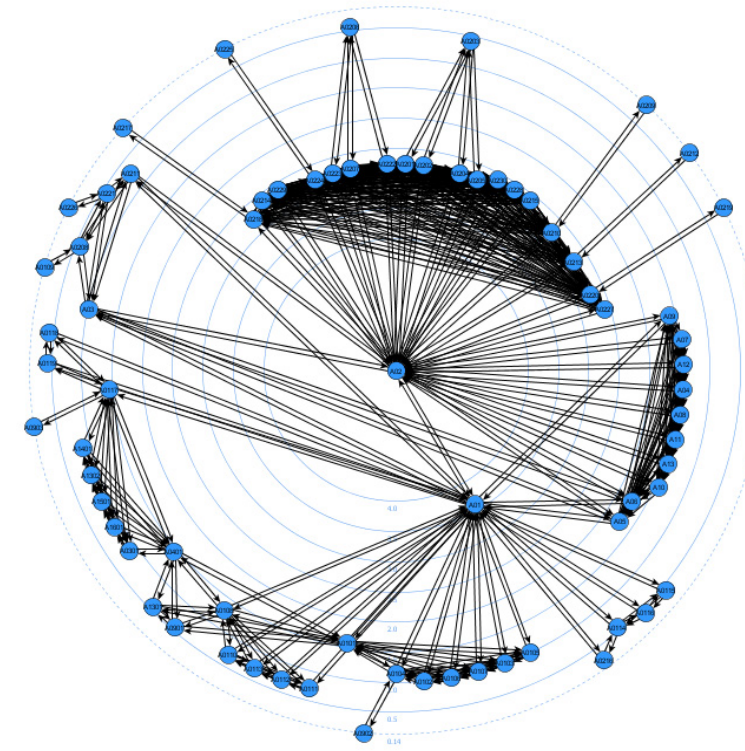

Figure 2. Collaboration based on degree centrality 
Degree centrality is calculated based on the equation, below. It indicates that a node that has many connections is most important in the network.

$$
C D(n i)=\sum_{j} x_{i j}
$$

Figure 2 shows a graphical representation of collaborative relationships among local governments. Each node indicates local governments and each link represents an interaction with a corresponding partner on regional projects for local economic development and public service delivery. As local governments are located in the middle, the values of degree centrality is higher, indicating that local governments located in the center have actively interacted with others for regional growth. The visualization in Figure 2 reveals that A02 (Kyonggi-do) and A01 (Seoul) play crucial roles in improving regional economics of the Seoul metropolitan area. The upper-level local governments, such Kyonggi-do and Seoul, mainly cooperate with many lower level local governments which belong to them. Additionally, they work together with other upper- and lower-level local governments that are located outside of the capital metropolitan area.

\subsubsection{Closeness Centrality}

Closeness centrality is calculated based on the equation, below. In the equation, $d(n i, n j)$ is defined as the geodesic distance connecting actor $i$ to actor $j$.

$$
C C(n i)=\frac{1}{\sum_{j}^{g} d\left(n i, n_{j}\right)}
$$

Closeness centrality is calculated based on the inverse of the length of the average shortest path between a node and all other nodes in the network (Wasserman \& Faust, 1994).

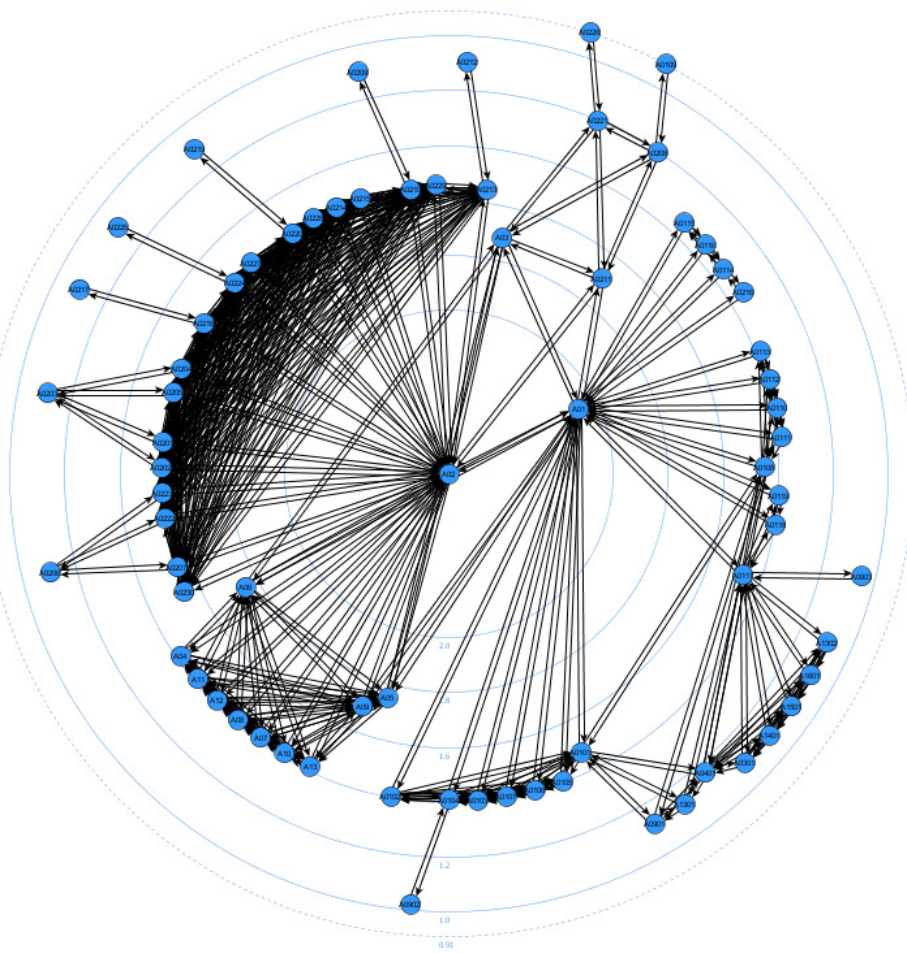

Figure 3. Collaboration based on closeness centrality

A node with high closeness centrality indicates that the node is relatively close to all other entities, meaning it can easily access resources or quickly contact to receive information from others.

In the visualization of Figure 3, the values of closeness centrality of the upper-level local governments are relatively high versus those of the lower-level counterparts. The top five local governments with higher closeness centrality values were A02 (Kyonggi-do), A01 (Seoul), A05 (Kangwon-do), A06 (Chungcheongbuk-do), and 
A03 (Incheon), respectively. This suggests that the roles of those upper-level local governments may be considered important for regional development in the metropolitan area. The upper-level local governments have relatively abundant financial capital. With a sound fiscal self-reliance ratio, those upper-level local governments financially support the lower-level local governments that belong to them, and can execute diverse projects and programs for regional growth. In particular, the findings provide information regarding the mechanism of the collaborative networks in the biggest metropolitan area in South Korea. Furthermore, these results suggest that the geographical factor is important in the selection of collaborative partners. Seoul, Kyonggi-do, Incheon-si, Kangwon-do, and Chungcheongbuk-do, which are geographically close, are more likely to collaborate with each other.

\subsubsection{Betweenness Centrality}

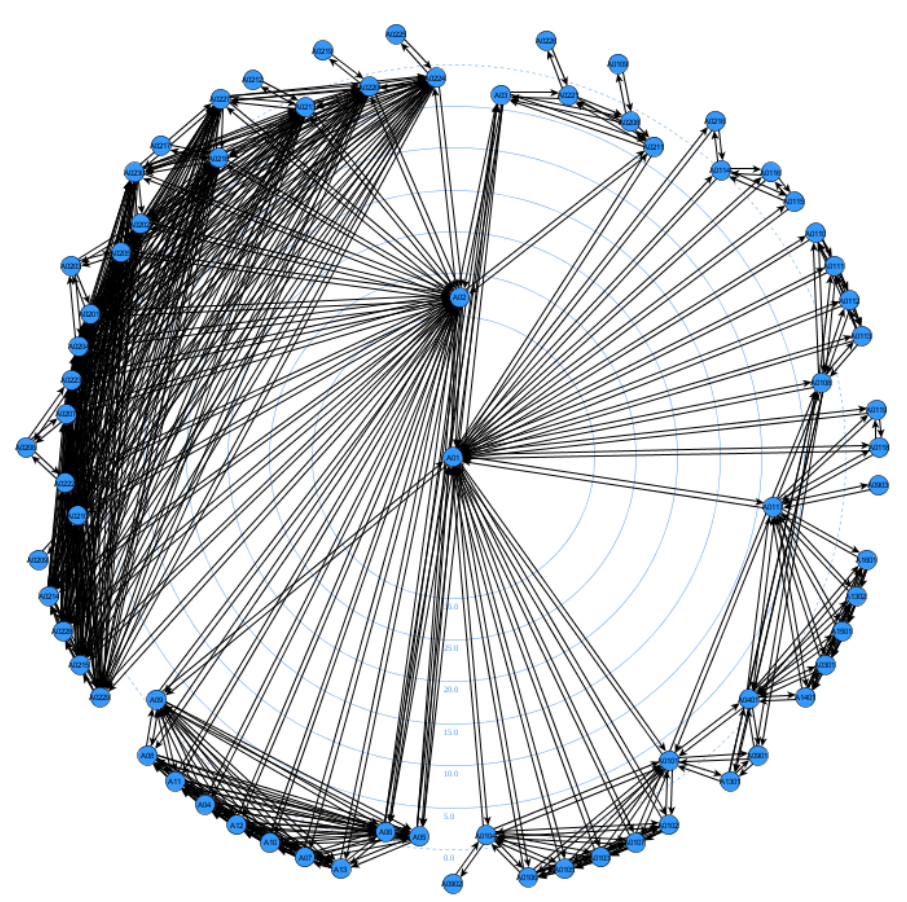

Figure 4. Collaboration based on betweenness centrality

Betweenness centrality is calculated based on the equation, below. In this equation, $g_{j k}$ is the number of geodesics connecting $\mathrm{j}$ and $\mathrm{k}$, and $g_{j k}\left(n_{i}\right)$ is the number of geodesics that actor $i$ is on.

$$
C B(n i)=\sum_{j<k} \frac{g j k(n i)}{g_{j k}}
$$

Betweenness centrality is measured by the number of times of a vertex occurs on a geodesic. That is, a node with the highest betweenness centrality value means that s/he should be located between many vertices via their geodesics, indicating that an actor or organization identified by betweenness centrality is between communications and information flow. In this case of the capital metropolitan area, the capital city (A01), Seoul, had the highest score of betweenness centrality, meaning that Seoul lies on important communication paths for diverse projects and programs regarding regional economic development and public service delivery in the capital metropolitan area. Furthermore, it means that Seoul can manipulate communicated information and control collaborative projects and programs among the participating local governments.

Additionally, contrary to the results of degree and closeness centrality, several lower-level local governments that belong to Seoul-Yangcheon-gu (A0117), Dongjak-gu (A0104), and Kangbuk (A0108)-are in the top 10 local governments with higher betweenness centrality scores. For example, Yangcheon-gu has actively established collaborative network relationships with municipalities that belong to other upper-level local governments, such as Dalseo-gu in Daegu and Yeonje-gu in Busan, as well as local jurisdictions within the same upper-level government, Seoul (A01). That is, the city has actively interacted with jurisdictions that are geographically both outside and within the capital metropolitan area. 
Finally, based on the results of degree, closeness, and betweenness centrality, the lower-level local governments that belong to Kyonggi-do are more likely to share their information on regional growth and to cooperate with each other for public service delivery (which is labeled in the format A02XX). The Kyonggi-do and municipalities that belong to this jurisdiction share a huge land area that should be developed and have a large population who need workplaces. For a long time, a large area of Kyonggi-do was designated as a limited development district in order to restrict development of Seoul Capital City. As the autonomy and authority of regional development have been delegated to individual local governments through a local self-governing system, Kyonggi-do has also carried forward diverse development plans with lower-level local governments within Kyonggi-do. Thus, the opportunities for collaborative development have increased in the area.

When implementing development projects between upper- and lower-level governments, generally the lower-level local jurisdictions are subject to the institutions and rules of the upper-level local governments. The upper-level government used to be seen as a brokerage who mediated in dispute that can occur in collaborative processes, and helped to communicate between/among lower-level local governments. Additionally, based on the findings, we can see that local governments in Kyonggi-do are more likely to communicate with each other for regional development. In addition, because Kyonggi-do is geographically located between two major upper level governments, Seoul and Incheon, Kyonggi-do is expected to play a brokerage role in bridging between/among local governments that belong to the two jurisdictions.

Table 2. Centrality ranking (Top 10 scores) in the capital metropolitan area

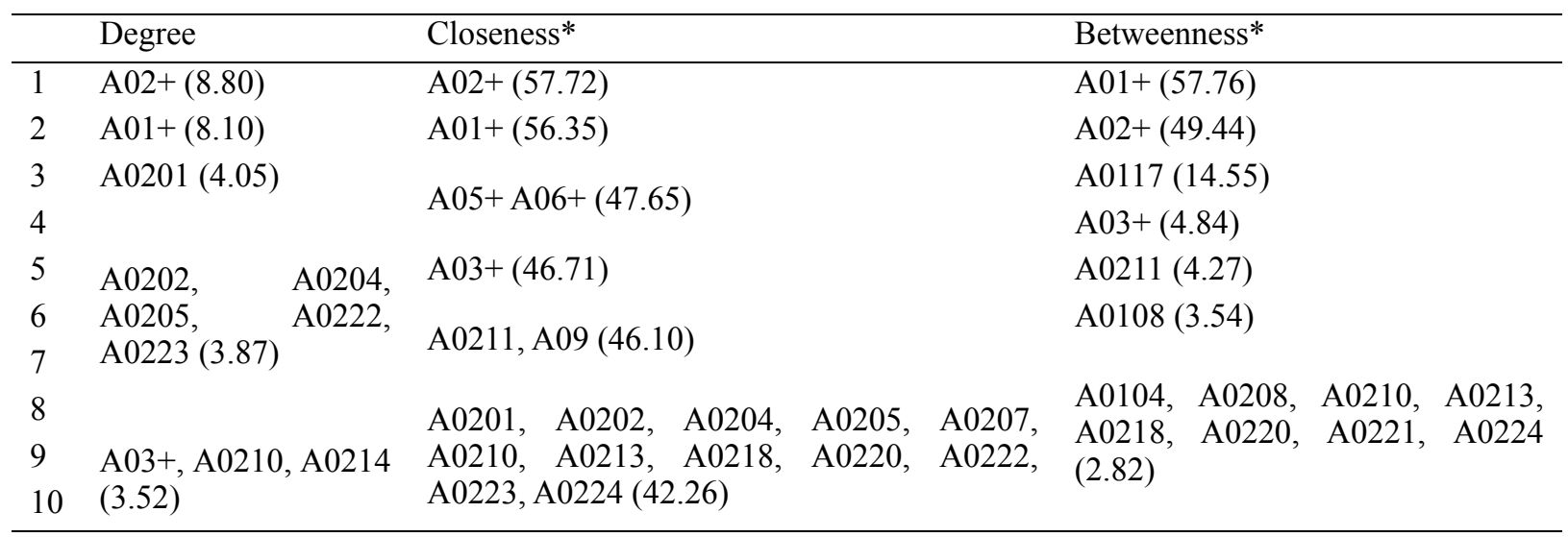

\footnotetext{
* For the names of local governments, see the Appendix

** Actors with "+" sign represent upper level local autonomy.

*** The values in parentheses are normalized values of each centrality.
}

Table 2 reports the local governments with the top 10 scores of centralities in the capital metropolitan area. The results in Table 2 confirm that the local actors that play important roles for regional collaborative projects are the upper-level local governments: A02 (Kyonggi-do), A01 (Seoul), and A03 (Incheon). In particular, the results demonstrate that A02 (Kyonggi-do) and A01 (Seoul) upper local governments played roles as network brokers; bridging local municipalities between two different geographic areas (see the results in betweenness centrality). This suggests that in the capital metropolitan area in South Korea, the upper-level local governments are located in positions that can manipulate or coordinate information and resources for regional economic development and efficient service delivery.

\section{Discussions}

This study tried to empirically examine the regional collaborative mechanism(s) for economic development and service delivery in a competitive environment, using social network analysis, beyond simply illustrating the phenomena of collaboration among local jurisdictions and normatively emphasizing the importance of voluntary networks. Since the local self-government system in South Korea was established in 1995, it has developed rapidly in terms of legal and institutional aspects. However, contrary to this external development, individual local governments have suffered from poor fiscal self-reliance ratios and have depended substantively on the central government. In order to overcome the problems with securing their local autonomy, voluntary collaborations among local municipalities for regional economic growth and public service delivery have 
occurred. In this sense, identifying the overall pattern of regional collaboration and investigating how individual local jurisdictions strategically behave and interact with their potential partners are quite critical in understanding the nature of regional collaboration approach which becomes a dominant growth strategy in Korea. Social network analysis allows us to link individual governments' actions and decisions to overall structure of collaboration. For example, this study demonstrates the upper-level local governments are located in more central position in overall collaboration network. This seems to contradict genuine network process, which is believed to be more horizontal association among network actors. However, existing literature in many other local autonomy contexts, the existence of key players in the network tend to be common phenomenon under more centralized system. And network structure in Korea prefers to have a central actor who can manipulate or coordinate information and resources for regional economic development and efficient service delivery. The findings from this study contribute to understanding the unique local self-government system and the regional mechanism of the biggest metropolitan area in South Korea. This study also provides a framework to explore whether the empirical findings are generalizable to other collaboration settings.

\section{Acknowledgements}

Foundation item: This work was supported by Kyonggi University Research Grant 2012 (No.: 2012-014). Author is grateful to the Kyonggi University, South Korea for financial support to carry out this work.

\section{References}

Agranoff, R., \& McGuire, M. (2003). Collaborative Public Management. Washington DC: Georgetown University Press.

Borgatti, S. P., Everett, M. G., \& Freeman, L. C. (2002). Ucinet for Windows: Software for Social Network Analysis. Harvard, MA: Analytic Technologies.

Burt, R. S. (2005). Brokerage and Closure: An Introduction to Social Capital. New York: Oxford University Press.

Coleman, J. S. (1988). Social Capital in the Creation of Human Capital. American Journal of Sociology, 94. Supplement: Organizations and Institutions: Sociological and Economic Approaches to the Analysis of Social Structure (pp. S95-S120).

Elisabeth, R. G., Adam, D. H., \& Mark, L. (2011). Political Homophiles and Collaboration in Regional Planning Networks. Working Paper prepared for presentation at the Annual Meeting of the Midwest Political Science Association (MPSA), Chicago, IL, March 31-April 3, 2011.

Feiock, R. (2004). Metropolitan Governance: Conflict, Competition, and Cooperation. Georgetown University Press.

Feiock, R. C., \& John, S. (2010). Self-Organizing Federalism: Collaborative Mechanisms to Mitigate Institutional Collective Action Dilemmas. Cambridge, MA: Cambridge University Press.

Gordon, V. (2007). Partners or Competitors? Perceptions of Regional Economic Development Cooperation in Illinois. Economic Development Quarterly, 21(1), 60-78. http://dx.doi.org/10.1177/0891242406291573

Granovetter, M. (1985). Economic Action and Social Structure. Journal of Sociology, 91(3), 481-493.

Gulati, R., \& Martin, G. (1999). Where Do Interorganizationl Networks Come From? American Journal of Sociology, 104(5), 1439-1493. http://dx.doi.org/10.1086/210179

Lee, Y. (2011). Economic Development Networks among Local Governments: The Structure of Collaboration Networks in Tampa Bay Metropolitan Area. International Review of Public Administration, 16(1), 113-134. http://dx.doi.org/10.1080/12264431.2011.10805188

Lee, Y., Richard, F., \& Lee, I. W. (2012). Interorganizational Collaboration Networks in Economic Development Policy: An Exponential Random Graph Model Analysis. Policy Studies Journal, 40(3), 547-573. http://dx.doi.org/10.1111/j.1541-0072.2012.00464.x

Oakerson, R. J. (1999). Governance Structures and Problem-Solving in Metropolitan Areas: Responding to (Downsian) Growth-Related Problems. Workshop in Political Theory and Policy Analysis. Indiana University, Bloomington.

Tiebout, C. (1961). An Economic Theory of Fiscal Decentralization. NBER, Public Finances, Needs, Sources and Utilization (pp. 79-96). Princeton Univ. Press.

Wasserman, S., \& Faust, K. (1994). Social Network Analysis: Methods and Applications. Cambridge, ENG and 
New York: Cambridge University Press. http://dx.doi.org/10.1017/CBO9780511815478

Wright, D. S. (1984). Managing the Intergovernmental Scene: The Changing Dramas of Federalism, Intergovernmental Relations and Intergovernmental Management. In W. B. Eddy (Ed.), Handbook of Organization Management. New York: Marcel Dekker.

\section{Appendix}

$<$ Upper Level Local Government with Top 10 Centrality Scores>

A01: Seoul-si

A02: Kyonggi-do

A03: Incheon-si

A05: Kangwon-do

A06: Chungcheongbuk-do

A09: Chollanam-do

<Lower Level Local Government with Top 10 Centrality Scores >

A0104: (Seoul-si) Dongjak

A0108: (Seoul-si) Kangbuk

A0117: (Seoul-si) Yangcheon

A0201: (Kyonggi-do) Gwangju

A0202: (Kyonggi-do) Icheon

A0204: (Kyonggi-do) Yeoju

A0205: (Kyonggi-do) Yangpyeong

A0207: (Kyonggi-do) Gwacheon

A0208: (Kyonggi-do) Gwangmyeong

A0210: (Kyonggi-do) Namyangju

A0211: (Kyonggi-do) Bucheon

A0213: (Kyonggi-do) Yangju

A0214: (Kyonggi-do) Yongin

A0218: (Kyonggi-do) Paju

A0220: (Kyonggi-do) Hwaseong

A0221: (Kyonggi-do) Siheung

A0222: (Kyonggi-do) Anyang

A0223: (Kyonggi-do) Gunpo

A0224: (Kyonggi-do) Pyeongtaek

\section{Copyrights}

Copyright for this article is retained by the author(s), with first publication rights granted to the journal.

This is an open-access article distributed under the terms and conditions of the Creative Commons Attribution license (http://creativecommons.org/licenses/by/3.0/). 